\title{
Espacios de salvación y prisión: Memoria narrativa y "colindancia" en La ciudad de los hombres de Cristina Rivera Garza.
}

\section{Spaces of Salvation and Imprisonment: Narrative Memory and "Adjacency" in La ciudad de los hombres by Cristina Rivera Garza.}

\begin{abstract}
Resumen
Desde el título de su colección de relatos, La frontera más distante (2008), la escritora mexicana Cristina Rivera Garza busca alejarnos de lo conocido y cercano; cada relato se distingue por esta premisa, pero es en "La ciudad de los hombres" donde la distancia es evocada para reclamar sobre un pasado. En este artículo se propone como eje de discusión el término memoria narrativa para apuntar la forma dialógica que el relato se enfrenta a los espacios clasificados, ya sea como civilización y/o barbarie en el siglo XIX latinoamericano. Rivera Garza retoma este binomio y presenta una crítica desde la "colindancia". En este trabajo se argumenta que este espacio heterotópico funciona como uno de salvación y prisión para la protagonista del relato.
\end{abstract}

Palabras claves Estudios de memoria, estudios de género, géneros literarios, heterotopías, civilización y barbarie, dialogismo.

\begin{abstract}
The title of the short-story collection, La frontera más distante (2008) is a point of departure for the Mexican writer Cristina Rivera Garza to distance the reader from the already known and proximate; each of the short stories distinguishes itself by this premise, but is in "La ciudad de los hombres" ("The City of Men") where distance is invoked to reclaim a past. In this article, narrative memory is proposed as a central dialogic concept to indicate the way this short story confronts those spaces classified as either civilization and/or barbarism
\end{abstract}


Catedral Tomada: Revista de crítica literaria latinoamericana / Journal of Latin American Literary Criticism Espacios de salvación y prisión: Memoria narrativa y "colindancia” en La ciudad de los hombres de Cristina Rivera Garza

during the $19^{\text {th }}$ century in Latin America. Rivera Garza recuperates this opposition and critiques it from the "adjacent". In this article the term is used in Spanish ("colindancia") to argue that this heterotopic space functions as one of salvation and imprisonment for the female protagonist of the story.

Keywords

Memory Studies, gender and genre studies, heterotopia, civilization and barbarism, dialogism.

Cristina Rivera Garza es escritora, académica, historiadora y poeta mexicana. Se graduó de la $\mathrm{UNAM}^{1}$ con un título en Sociología y de la Universidad de Houston con un doctorado en Historia (Benmiloud y LaraAlengrin 21). A partir de su tesis doctoral ${ }^{2}$ escribe una novela sobre el manicomio de La Castañeda inaugurado en México en 1910 por Porfirio Díaz en la Ciudad de México: Nadie me verá llorar (1999). Esta obra fue merecedora de varios premios importantes y reconocimiento internacional. Su trayectoria no está sólo marcada por galardones, sino también por explorar distintos géneros de escritura, como argumenta Karin Benmiloud y Alba Lara-Alengrin sobre la obra de Rivera Garza: "[...] la escritora aúna y armoniza, según los contextos, ficción documental, novela histórica, narrativa metaficcional, prosa poética, literatura conceptual y escritura experimental, explorando sin tregua las fronteras de la legibilidad y de la textualidad" (22). Los onces relatos de La frontera más distante (2008) son una prueba ejemplar de esta caracterización. En esta publicación la autora nos entrega una conversación entre la novela, el ensayo, la investigación histórica, la poesía y combinaciones formales entre estos géneros. Si bien la transgresión de formas es evidente, el diálogo entre distintas temporalidades y memorias narrativas es una estrategia literaria no del todo obvia. En "La ciudad de los hombres" -el relato ${ }^{3}$ escogido para este análisis -es particularmente intrigante que, si bien la autora busca una narrativa alejada de normas formales, Rivera Garza retoma la oposición “civilización y barbarie" - un binomio que implica oposiciones rígidas.

\footnotetext{
${ }^{1}$ Universidad Nacional Autónoma de México.

2 The Masters of the Streets. Bodies, Power and Modernity in Mexico, 1867-1930 (1995).

${ }^{3}$ Aunque por su extensión de 28 páginas y desarrollo puede considerarse una novella.
} 
El término memoria narrativa se plantea en este artículo como un encuentro entre el pasado y el presente literario de un corpus latinoamericano. "La ciudad de los hombres" es un cuento que nos acerca con el pasado, con la memoria narrativa, a partir de la referencia con obras que han sido consideradas canónicas en estudios de literatura y cultura latinoamericana, tales como, Facundo- civilización y barbarie ${ }^{4}$ publicada en 1845 por el escritor argentino Domingo Faustino Sarmiento, y La Vorágine escrita por el colombiano José Eustasio Rivera en 1924. Estas dos obras en particular son ejemplos paradigmáticos de la dicotomía civilización-barbarie en América Latina del siglo XIX y XX. Se eligen estas obras en específico para demarcar un diálogo con el pasado desde parámetros canónicos, pero también para plantear las coordenadas formales e ideológicas que la autora busca replantear.

Cristina Rivera Garza en La frontera más distante no nombra los espacios, se distancia de alusiones regionales para proveer una mirada a lo emblemático. Debido a esta estrategia, en este trabajo el estudio de la intertextualidad no sólo es un análisis de fuentes, sino de memoria. Al marcar estas alusiones se busca situar esa memoria que M.M Bajtín les otorga a los géneros. Además, se argumenta que estos ecos son una memoria narrativa que se deslinda de especificidades para enfocarse en la memoria cultural y narrativa que se ha convertido este canon en Latinoamérica.

Asimismo, en los próximos apartados de este artículo, se indaga en la manera en que se reformula en el relato la dicotomía civilización y barbarie a través del género femenino. Esta estrategia incita a rememorar sobre esta tradición desde posturas que la tradición deliberadamente posicionó en el olvido. Las referencias que hace Rivera Garza en los dos cuentos sobre estas obras canónicas

${ }^{4}$ Esta obra se publica como folletín en el periódico chileno El Progreso entre mayo a junio de 1845, con el título de Civilización y barbarie. Vida de Juan Facundo Quiroga. La serie se transforma en libro y aparece con un nuevo título: Civilización y barbarie. Vida de Juan Facundo Quiroga. Y aspecto físico, costumbres y hábitos de la República Argentina. En este trabajo la obra de Sarmiento se cita usando una abreviación de ediciones posteriores: Facundo - civilización y barbarie. 
Catedral Tomada: Revista de crítica literaria latinoamericana / Journal of Latin American Literary Criticism Espacios de salvación y prisión: Memoria narrativa y "colindancia” en La ciudad de los hombres de Cristina Rivera Garza

son planteadas a través de la intertextualidad y memoria exponiéndolas desde la perspectiva de las mujeres y su posición en la "colindancia" —un concepto, territorio, que se analizará en este artículo como un espacio antitético, heterotópico y crítico en los relatos de la escritora mexicana.

\section{La ciudad de los hombres: Ecos del siglo XIX latinoamericano.}

La frontera más distante es la tercera colección de cuentos de Rivera Garza, vale mencionar sus otros dos libros de cuentos anteriores a éste: La guerra no importa publicado en 1991 y Ningún reloj cuenta esto del 2002. En el libro que atañe este artículo, la escritora mexicana propone la disolución de oposiciones y el distanciamiento de rasgos regionales, es decir, de ubicaciones espaciotemporales e históricas - características a su vez centrales de "La ciudad de los hombres". En el caso de este cuento, esta última característica se revela con las breves descripciones de la ciudad, por lo que la autora elude la identificación con una ciudad o territorio específico; presentando un rechazo premeditado por la nominación de espacios y nombres propios tanto de los lugares como de las personas. Esta desidentificación permite asimismo explorar el relato desde coordenadas regionales más amplias; le da libertad de ir más allá del espacio mexicano que es el más cercano al origen de la autora.

La preferencia por la ambigüedad y dislocamiento es notoria desde los primeros párrafos del relato. Por ejemplo, al inicio se introduce a la protagonista sin dar su nombre - periodista a quien asignaron una serie de reportajes sobre una ciudad que excluye a las mujeres - , en la narración no se dan detalles de su lugar de partida; lo que sí queda claro es que la visita a la ciudad se plantea como oficial, ya que es el editor del periódico quien le consigue los permisos para entrar. Por otro lado, sobre el trabajo que le han encomendado a la periodista recae grandes expectativas, incluso se pretende que sea una serie periodística, 
como el jefe de redacción señala: "Un reportaje de la Ciudad de los Hombres desde el punto de vista de una mujer tendría, le había dicho el periodista, un éxito asegurado" (Rivera Garza, La frontera 57).

Siguiendo con la ubicación espacial, aunque la periodista da cuenta de la ciudad a donde llega, estas descripciones no le permiten al lector(a) hallar pistas para identificar semejanzas con un espacio en concreto, con una sociedad específica, ni incluye características distintivas, que seguramente desearía el periódico para el que trabaja: "Los altos edificios. Las calles amplias. Las hileras de autos $[\ldots]$ Los semáforos. Las gotas de agua sobre los parabrisas. Los rostros desdibujados detrás de todo eso" (59-60). Esta cita da cuenta precisamente cómo las descripciones de los lugares y las personas son cortas, pausadas y con pocos adjetivos, características permanentes en el cuento. Al describir sus habitantes, también es característico la falta de adjetivos, tanto así que a ninguno se le llama por su nombre propio, por algún gentilicio, son descritos únicamente como "Hombre", "El Hombre de la sonrisa", "Hombre viejo" o "Joven". En otras ocasiones se les nombra con base a sus profesiones, "Periodista", "Taxista", "Mesero" y "Boxeador".

Esta ausencia de detalles y descripciones específicas de la ciudad y de quienes la habitan, evidencia la distancia que la narrativa de Cristina Rivera Garza hace para no llegar a una obvia identificación cultural. En cuanto a esta posición, la autora ha afirmado en una entrevista realizada por Jorge Luis Herrera para la Revista Universo del Búho: “[...] si los nombres en sí mismos tienen una carga cultural enorme y las identidades fluyen y son relacionales, por qué no designar a estos personajes por lo que sus acciones y sus prácticas dictan en momentos distintos" (50). Los personajes sin nombre plantean la eliminación de una genealogía y de un lugar de origen. Además, la mención de profesiones en lugar de nombres propios propone clasificaciones inestables. Así, esta elección literaria, relacionada con las nominaciones de las personas, del territorio y de los espacios, indican inicialmente un rechazo a una "carga" cultural, como la misma Rivera Garza afirma. 
Catedral Tomada: Revista de crítica literaria latinoamericana / Journal of Latin American Literary Criticism Espacios de salvación y prisión: Memoria narrativa y "colindancia” en La ciudad de los hombres de Cristina Rivera Garza

Es importante notar que en La frontera más distante Rivera Garza presenta en sus relatos posturas críticas sobre el concepto "fronteras", desde una mirada cultural y literaria; precisamente, el título de la colección manifiesta esta temática que se hace recurrente en los cuentos. Así entonces, el libro propone desafiar discursos sobre la permeabilidad de las fronteras. Especialmente aquellos discursos que las han definido como armoniosas, naturales de nuestra época, como lo ha argumentado Rivera Garza: “[...] no son espacios y/o procesos de combinación armoniosa o sincretismos naturales -son, en cambio, entendidos en toda su radicalidad, campos de cruenta batalla-. Son espacios y/o procesos de extremo" ("Diaspóricos, fronterizos"). Es desde esta discordia, desde estos campos de batalla, que los relatos de la autora plantean su posición en relación a la ubicuidad cultural y política de las fronteras. Es de esta forma que se propone que la caracterización de la ciudad como "civilizada" y la selva como "inhumana" en "La ciudad de los hombres" permite tomar este cuento como eje para explorar, revisar y analizar desde el siglo XXI, las fronteras y las oposiciones canónicas propuestas en el siglo XIX.

En Facundo -civilización y barbarie, Domingo Faustino Sarmiento debatió sobre lo que sucedía en Argentina bajo el gobierno de Juan Manuel de Rosas (1835-1852), a través de propuestas políticas y reflexiones sobre una identidad deseada: europeizada y principalmente urbana, es decir "civilizada":

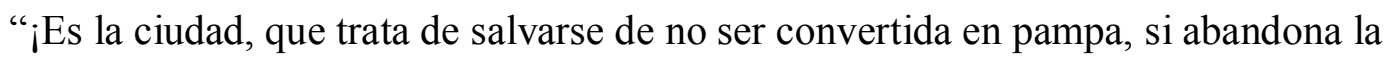
educación que la liga al mundo civilizado!” (204). Esta corriente de pensamiento posiciona la ciudad con lo letrado y los valores de la civilización. En cuanto a la concepción de lo "civilizado" Julio Ramos en su estudio sobre Facundo argumenta: "Para Sarmiento [...] la ciudad (casi siempre en negrillas) era un espacio utópico: lugar de una sociedad idealmente moderna y de una vida pública racionalizada. De ahí que en Sarmiento podamos leer etimológicamente el concepto de la 'civilización' -y de la 'política' - en su relación con 'ciudad"” (221). Para Sarmiento la civilización estaba en Buenos Aires y no en la pampa (la barbarie). Debido a la situación cambiante del continente americano estas 
características identitarias funcionaron como base para la formación de naciones durante el siglo XIX en Latinoamérica; en "La ciudad de los hombres" la autora explora de manera crítica la oposición "civilización y barbarie" planteada por Sarmiento. El eco literario se hace evidente a través de la evocación de rechazo a un grupo de personas (en este caso las mujeres), las menciones de la ciudad como "proyecto" y la constante alusión a la división entre la ciudad y la selva que la rodea.

Un acercamiento a través de la perspectiva de memoria narrativa permite aproximarse a la dicotomía "civilización y barbarie" en La ciudad de los hombres en tanto ésta da cuenta de la persistencia de discursos divisorios en América Latina, dicotomía que continúa siendo tema para abordar en la literatura latinoamericana contemporánea. En el caso del trabajo de Rivera Garza, la manera en que se tensan los dos términos "civilización y barbarie" permite explorar no sólo la forma de la obra, sino también el bagaje cultural que la precede. Es así como, un análisis de este tipo despliega una historia de los discursos, las maneras de pensar y de un contexto que hace parte de nuestra memoria cultural latinoamericana. Siguiendo lo anterior, la memoria narrativa es una mirada crítica que se aborda desde los textos. La memoria en este compendio funciona como una mirada de análisis, un intento de rememoración; es un acto reflexivo y una búsqueda de razones que propone cuestionamientos. No sólo evoca los discursos hasta ahora discutidos, sino también llega a alterarlos, por lo que responde a las demandas de contextos contemporáneos. Así, "La ciudad hombres" de Rivera Garza propone una lectura en la que volver sobre referencias, como las del texto de Sarmiento, es también una estrategia para enfrentarlas.

Como se había mencionado anteriormente, el diálogo que "La ciudad de los hombres" propone en relación con la dicotomía canónica ya mencionada, que se estableció desde hace dos siglos en el territorio americano, da cuenta de la persistencia de este modelo de pensamiento en América Latina, que también ha sido planteado por otros escritores y lo han afirmado estudios críticos sobre la tradición literaria latinoamericana. Roberto González Echevarría en Myth and 
Catedral Tomada: Revista de crítica literaria latinoamericana / Journal of Latin American Literary Criticism Espacios de salvación y prisión: Memoria narrativa y "colindancia” en La ciudad de los hombres de Cristina Rivera Garza

Archive: A Theory of Latin American Narrative ${ }^{5}$ y en The Voice of the Masters: Writing and Authority in Modern Latin American Literature, destaca la existencia de la dicotomía "civilización y barbarie" en debates relacionados con la cultura latinoamericana ${ }^{6}$ y sobre su rol fundacional del género "novela de dictador":

The most recent evidence of Facundo's lasting relevance are the debates around the figure of Caliban as symbol of Latin American culture, a polemic whose origin is found in Sarmiento. Another, perhaps more durable resurgence is the proliferation of dictator-novels in Latin America, all of which have their common source in Facundo. (Echevarría 98)

$\mathrm{Su}$ trascendencia a su vez es indiscutible en la literatura y cultura latinoamericana, como lo han planteado estudios críticos sobre la tradición literaria latinoamericana: Jean Franco en, The Modern Culture of Latin America: Society and the Artist y Carlos Fuentes en La nueva novela hispanoamericana ${ }^{7}$.

La aportación de la antinomia —civilización y barbarie- al discurso político, cultural y literario latinoamericano responde a lo que M.M Bajtín atribuye al contexto dialógico del discurso y a la re-elaboración infinita de los géneros literarios en Problems of Dostoevsky's Poetics: "Genre lives in the present, but it always remembers the past, its beginnings" (142). La recontextualización de "civilización y barbarie" de la obra Facundo, que hace

\footnotetext{
${ }^{5}$ Mito y archivo: una teoría de la narrativa latinoamericana. Su primera publicación fue en inglés en 1990, pero el libro no se publicó en español hasta el año 2000 por el Fondo de Cultura Económica de México.

${ }^{6}$ Echeverría destaca de manera contundente la proyección de la novela Facundo, debido a los planteamientos de Sarmiento sobre el desplazamiento del "otro extranjero" por "el otro interno", que el "salvaje" no es sólo el que viene de ciertos países europeos, sino que también está en "nuestros" territorios (Echevarría 93-98).

7 Franco afirma que Facundo específicamente establece la identificación de la ciudad con lo civilizado y valores europeos; la barbarie, lo espacios rurales, con lo iletrado y sin cultura (6). Fuentes argumenta que la obra de Sarmiento refuerza el poder protagonista y amenazante de la naturaleza y críticas en respuesta a esta configuración en la nueva novela hispanoamericana (10).
} 
Rivera Garza, marca su enfrentamiento con estos "inicios" ideológicos y genéricos. Esto se da debido a que la autora reconoce la indiscutible presencia de la oposición en el contexto literario y socio-histórico latinoamericano. Esta elección provee distintas vertientes de reflexión sobre cómo esta dicotomía se convirtió en un esquema de juicio de los problemas económicos y sociopolíticos de América Latina. "La ciudad de los hombres" permite ampliar el análisis sobre esta memoria narrativa y da cuenta de su ubicuidad en el contexto latinoamericano.

\section{El proyecto utópico de la "civilización".}

Las descripciones que provee la periodista en "La ciudad de los hombres", protagonista del relato y narradora de los acontecimientos, sobre la ciudad son sobrias, sin embargo, lo que queda claro es que es un espacio urbano: hay rascacielos, una hemeroteca, hoteles y hospitales. Al mismo tiempo, la caracteriza como un lugar en construcción, un "proyecto" que ha provocado el interés del público internacional, como lo demuestra la presencia de la periodista y su asignación. Las descripciones que la periodista hace de la ciudad tienen relación con lo que propone Domingo Faustino Sarmiento en Facundo, en relación al deber ser de las ciudades, por ende, de los espacios "civilizados", es decir, estas deben estar compuestas por: "[...] los talleres de las artes, las tiendas del comercio, las escuelas y colegios, los juzgados, todo lo que caracteriza en fin, a los pueblos cultos" (Sarmiento 17).

Por otro lado, en el relato de Rivera Garza, los habitantes de la ciudad evocan el concepto de "civilización" al referirse a la ciudad como lugar utópico que dará una vida mejor a los hombres, por ejemplo, cuando la periodista, protagonista del cuento, asiste a una cena de bienvenida que organizan para ella artistas locales, señala la narradora que: "En el salón no se comentaba acerca de la 
Catedral Tomada: Revista de crítica literaria latinoamericana / Journal of Latin American Literary Criticism Espacios de salvación y prisión: Memoria narrativa y "colindancia” en La ciudad de los hombres de Cristina Rivera Garza

ciudad, sino del proyecto. La amplitud de sus calles. Las líneas verticales de sus edificios. La combinación entre el incesante mundo del comercio y la búsqueda de caminos espirituales más profundos, más serenos" (La frontera 66). También, en las entrevistas que realiza la periodista a un "Profesor Universitario", a un "Diputado" y un "Boxeador", éstos le describen sus vidas en la ciudad de los hombres como: "[...] buenas, sanas, exitosas. Sus traslados, desde distintas partes del mundo, habían sido, de acuerdo con los tres, para bien” (65).

Lo anterior evidencia cómo la ciudad es ordenada y habitada por un grupo de personas que comparten una ideología. Sin embargo, la selva que rodea la ciudad es lo opuesto a ésta. Es calificada como un lugar inconstante que tiene que ser vigilado. Es frondosa, fétida, inhabitable y amenazante. También es fragmentaria, carece de centro y es habitada por mujeres que han perdido el entendimiento, - de esto último se da cuenta la periodista hacia la mitad de su estadía de investigación en la ciudad, cuando ella visita la selva-.

La primera vez que escucha sobre este lugar es gracias al mesero del hotel donde se hospeda. Se entera además que ella no es la primera periodista que visita la ciudad, información que tampoco tenía el editor del periódico en el que trabaja:

- ¿Las otras? [...]

- Las otras periodistas, por supuesto - dijo él [el mesero]-. Las que vinieron antes que usted $[\ldots]$

- ¿Y cuánto tiempo se quedaron las otras? [...]

- Eso no lo sé [...] Pero fue más tiempo del que pensaban.

- ¿Y cuántas periodistas eran? [...]

- Eran sólo dos - mencionó - Tal vez tres. (61)

Las nuevas revelaciones le suscitan a la periodista múltiples preguntas, por lo que decide investigar en la "Hemeroteca" central de la ciudad. Las 
indagaciones que hace no fueron fructíferas, ya que ningún periódico foráneo había publicado reportajes que confirmaran visitas de "otras" periodistas. Es preciso señalar que el uso de las "otras" omite sus nombres propios ${ }^{8}$ y elimina su individualidad. Además, su importancia es minimizada, como lo enfatiza la actitud del mesero al afirmar que no está seguro del número de mujeres que visitaron la ciudad.

Inicialmente, la falta de evidencias periodísticas sobre las visitas de las otras periodistas provoca dudas en la protagonista sobre la información dada por el mesero. Sin embargo, en un segundo encuentro con él, las revelaciones se consolidan, al igual que la amenaza a la que inevitablemente se ve sujeta:

- ¿Y dónde se quedaron? - le preguntó [al muchacho] [...]

- ¿Dónde se quedaron quiénes? [...]

- Las periodistas que me mencionaste hace días.

- Nadie supo - mencionó después de un rato [...]

- La selva está cerca - murmuró el muchacho sin volverse a verla -. Cuando alguien quiere esconderse por lo regular va ahí. A la selva. [...] (71-71)

"El muchacho" no le da información acerca de los motivos que tuvieron las "otras" para esconderse, pero el rechazo que percibe la periodista desde su llegada a la ciudad le permite seguir reuniendo evidencias sobre sus hipótesis:

Mientras la esperaba [la periodista a su maleta] recordó la mueca en la cara del oficial [de migración]. La había mirado de arriba abajo al preguntarle por el motivo de su viaje. Ella respondió con la verdad: trabajo. El oficial guardó silencio, la miró ahora de abajo hacia arriba, y

\footnotetext{
${ }^{8} \mathrm{Al}$ igual que los demás personajes del cuento.
} 
Catedral Tomada: Revista de crítica literaria latinoamericana / Journal of Latin American Literary Criticism Espacios de salvación y prisión: Memoria narrativa y "colindancia” en La ciudad de los hombres de Cristina Rivera Garza

firmó papeles parsimoniosamente, sin ocultar la mueca que acercaba la comisura izquierda de su boca hacia su pómulo. (58)

Este tipo de sucesos de rechazo y las revelaciones expresadas por el mesero en el segundo encuentro lleva a la periodista a una conclusión: sus colegas -aún sin conocerlas- fueron obligadas a refugiarse en la selva. Adicionalmente, la narración simultánea en la voz narrativa del editor confirma al lector(a) esta hipótesis.

A partir del descubrimiento de las "otras", de confirmar la información del mesero, la voz de la protagonista es intercalada con la narración de sus cartas, las cuales describen los acontecimientos que ha vivido en la ciudad y que son leídas posteriormente por el editor: "En los reportajes que, tiempo después, recibió el Jefe de redacción [...]" (70). La voz del narrador omnisciente se intercala, entre lo que ocurre en la ciudad y los sucesos fuera de ella. Se entrecruzan las voces, por lo que en el cuento se hacen presentes dos narradores: uno omnisciente y uno en primera persona - la protagonista; su voz se despliega a través de las cartas al editor y el diálogo con los hombres de la ciudad.

Esta estrategia narrativa interrumpe y desmantela el misterio del cuento. A partir de los descubrimientos de la protagonista sobre las "otras" el papel opresivo de la ciudad es incuestionable. Para empezar, la mirada que ofrece el narrador omnisciente sobre la reportera, da cuenta de los objetivos que tiene el reportaje, las razones por las cuales fue enviada la periodista a la ciudad y los resultados que espera el periódico. Pero también, en que después de las revelaciones del mesero, los esfuerzos de la periodista se centran en encontrar a las periodistas. Posteriormente, a través del editor, es decir, en los detalles que incluye en sus cartas, la reportera anuncia sin reparo la amenaza de la que está siendo víctima, la persecución que la lleva a predecir su eventual desaparición: 
Meses después, en los reportajes que llegaron, sin firma, a las oficinas de su periódico, se encontraría la descripción de lo que sucedió al abrir la puerta de su cuarto ${ }^{9}$ : El sobre, blanco y rectangular, contrastaba con el color oscuro de la alfombra. Era imposible no verlo. Lo recogí: ningún nombre. Lo abrí. La nota era breve e iba escrita con una letra pequeña e irregular. Aléjese. Váyase de este lugar. Pronto ya no tendrá manera de escapar $[. .$.$] Tenía miedo [...] (64).$

Este modo de narrar interrumpe la lectura lineal del cuento, pero establece la rivalidad entre la ciudad y la selva. Mayra Luna ${ }^{10}$ en su análisis de la obra, plantea que el cuento de Rivera Garza no sigue las formas tradicionales de su género, no cuenta dos historias, ni una de ellas tiene un final revelador, las dos historias son implícitas:

Una que se escribe para desdibujar a la historia 'original'; por tanto, es implícita desde su inicio. La otra historia implícita, aquella que se encuentra entretejida en el relato, que se esconde en el lenguaje, es, más que otra historia, la evocación de un estado [...] Estados similares a los que provoca la contemplación de una catástrofe desoladora, pero ajena. (Cantú 351)

Concuerdo con Luna en su análisis de la estructura no tradicional del cuento, en cuanto a su argumento sobre los "estados" me interesa en la medida que destaca la presencia de elementos y tonos desoladores, amenazantes y catastróficos. En el acercamiento que he hecho respecto a la forma del relato, encuentro que éste es una crítica a la función de oposiciones divisorias en la sociedad que narra el cuento. "La ciudad de los hombres" presenta deseos de

\footnotetext{
${ }^{9}$ Después del primer encuentro con el mesero.

${ }^{10}$ Citada en "El margen como centro: Exploración del espacio en dos cuentos de La frontera más distante de Cristina Rivera Garza” de Irma Cantú.
} 
Catedral Tomada: Revista de crítica literaria latinoamericana / Journal of Latin American Literary Criticism Espacios de salvación y prisión: Memoria narrativa y "colindancia” en La ciudad de los hombres de Cristina Rivera Garza

orden, éxito, salud, estrictamente alcanzables mediante el control, la división y la exclusión de las mujeres. La selva, en femenino, como la presenta Rivera Garza, busca irrumpir este orden. De manera que la autora a través también de esta disrupción formal, se enfrenta a "civilización y barbarie" y debate este pensamiento fundacional de las naciones latinoamericanas.

La intertextualidad en el cuento se da entonces a través del reconocimiento de la tradición literaria y su propia manera de leerla. En su análisis del diálogo entre textos, de las posturas sobre el dialogismo de Bajtín en "Bajtín, la palabra, el diálogo y la novela.”, Julia Kristeva argumenta que el filósofo: “[...] sitúa el texto en la historia y en la sociedad, consideradas a su vez como textos que el escritor lee y en los cuales se inserta reescribiéndolos" (2). Esta manera de escribir y plantear una obra literaria, que bien delinea Bajtín desde su perspectiva dialógica, es una característica que Rivera Garza explora. Esta postura además está acompañada por un intento de disrupción, ya que entre más se acerca la protagonista a la selva más cerca está de escapar de la vigilancia de la ciudad, por lo que se evidencia que alterar la división ciudad-selva se vuelve un objetivo principal para Rivera Garza en este cuento.

\section{La selva: un acercamiento desde la noción de la "colindancia".}

El mesero, personaje que ya he mencionado anteriormente, es elusivo en las respuestas que da a la reportera, en la manera en que se refiere a las periodistas y al expresar aparentemente que desconoce lo sucedido o el paradero de estas mujeres. Sin embargo, este supuesto desconocimiento o su falta de colaboración en la investigación es pasajero, ya que después de la segunda entrevista con la protagonista, éste aparece donde ella sin anunciarse: “- Tiene que venir conmigo - susurró el mesero mientras colocaba su mano sobre el codo y, empujando con suavidad, la llevaba fuera de su habitación -. Confíe en mí [...]" (73); le venda 
los ojos, la sube en un auto y la lleva a la selva con las “otras", quienes la esperan en una choza localizada bajo frondas verdes. (74)

Los detalles de su único encuentro con sus colegas desaparecidas también son relatados en los reportajes posteriores. En las narraciones, las descripciones que le da a la selva están relacionadas con el de lugares inconstantes: "En las afueras del orden se desarrolla, con gran obstinación, otro orden. No se trata de una ciudad alterna propiamente dicha, sino de una serie de anti-ciudades que, diseminadas a lo largo de los estrechos fronterizos, sobreviven en constante movimiento [...]" (75). En estos lugares localizados en "las afueras del orden" están detenidas las reporteras.

Las descripciones de estas "anti-ciudades", es decir de la selva, conllevan a una escritura "colindante" que Rivera Garza favorece. Así explica la autora en una entrevista de Yanet Aguilar Sosa para el periódico mexicano El Universal: "Hay un término que a mí me gusta mucho, el de escritura colindante, porque remite a un espacio donde no hay oposición, sino que es un terreno que todavía no está vigilado, o que por algún momento se ha escapado del ojo vigilante de los grandes clasificadores, [...] esos son terrenos de radical libertad creativa" ("La escritura"). Este tipo de escritura plantea escapes, lindes, pero también a partir de las designaciones de Rivera Garza, se puede considerar como una estrategia para escapar de las formas de control y vigilancia de la ciudad.

Debido a la apuesta narrativa de la autora en este cuento, que busca alejarse de limitaciones en cuanto la escritura, el término "colindancia" — la condición de lo "colindante" - genera una mirada crítica que permite analizar su interés por desafiar el control, las clasificaciones, las divisiones y las fronteras. A través de "La ciudad de los hombres", encuentro que el término "colindancia", describe cómo las "anti-ciudades" son una estrategia para deslindarse de la ciudad, escapar su control, rechazar la estabilidad a través de incesantes movimientos, como lo señala el cuento: "Fundadas y abandonas casi al mismo tiempo, esos caseríos sólo pueden existir sino son detectados por los distintos sistemas de vigilancia de la ciudad. Pasar desapercibidas es, luego entonces, su 
Catedral Tomada: Revista de crítica literaria latinoamericana / Journal of Latin American Literary Criticism Espacios de salvación y prisión: Memoria narrativa y "colindancia” en La ciudad de los hombres de Cristina Rivera Garza

principal objetivo" (Rivera Graza, La frontera 75). Estas características describen esos espacios de "resistencia" que las mujeres habitan para intentar mantenerse al margen de la ciudad y sus habitantes. Las diferencias destacadas plantean que, si la ciudad de los hombres es concebida como un "proyecto" utópico, las "anticiudades" de las mujeres son "heterotopías". Los caseríos o "anti-ciudades" de "La ciudad de los hombres" se asemejan a los espacios heterotópicos propuestos por Michel Foucault en "Of other Spaces"11 y en el prefacio de The Order of Things.

En la ciudad de los hombres, la selva y sus "anti-ciudades" se presentan en un principio como espacios de escape de la vigilancia, de posible resistencia y libertad, sin embargo, es el "mesero" el que dirige a la periodista a la selva y es el "chofer" el que la abandona en este lugar hacia el final del relato. Estas acciones dan cuenta que la selva también está bajo el control de los hombres — no sólo la ciudad; las mujeres continúan siendo vigiladas por el "proyecto" en las "anticiudades", porque son "colindantes" a la ciudad. Es de esta forma que la "colindancia" en los textos de Rivera Garza puede plantearse como una respuesta a las conclusiones sobre las diferencias entre las "utopías" y las "heterotopías" formuladas por Foucault. En "Of Other Spaces" Foucault plantea seis principios sobre estos espacios. El primero marca la distinción intrínseca entre las utopías y heterotopías:

First there are the utopias. Utopias are sites with no real place. [...] There are also, probably in every culture, in every civilization, real places places that do exist and that are formed in the very founding of society which are something like counter-sites [...] Because these places are absolutely different from all the sites that they reflect and speak about, I

\footnotetext{
${ }^{11}$ A pesar de nombrarlas en dos ocasiones, sólo es en su conferencia "Of Other Spaces"- dictada en 1967 y publicada en 1984 - donde describe las heterotopías a través de seis principios. Es relevante también explorarlas teniendo en cuenta que la conferencia fue publicada como un artículo póstumo sin permiso del filósofo.
} 
shall call them, by way of contrast to utopias, heterotopias. ("Of the Other")

Las mujeres son excluidas de la ciudad de los hombres porque como proyecto utópico éste busca que sus habitantes, los hombres, "logren éxito y vidas sanas", que no lo permitiría si las mujeres habitaran la ciudad. Este objetivo es aún un anhelo, pues la ciudad, al contrario de las "anti-ciudades" - de la selva -, es una "utopía", un lugar "no real". La ciudad de los hombres - a pesar de que excluye a las mujeres, lo cual es una de sus premisas para alcanzar sus objetivos -, es "un proyecto" que incluso todavía no funciona por completo como lo destaca "El Hombre Sonriente" cuando se refiere a sus líneas telefónicas: "El servicio puede ser pésimo a veces - dijo, por toda explicación-. No todo está resuelto es nuestra ciudad, como se puede imaginar" (La frontera 65 ).

Este estado de "imperfección" también se ve claramente cuando la periodista es testigo del control de sus habitantes, ya que la ciudad no sólo excluye a las mujeres, sino que a través de la normalización de sus ciudadanos busca un control absoluto de aquellos que la habitan. Por ejemplo, una mañana, hacia la mitad de su estadía, la periodista es despertada por una música indescriptible. Si bien es tan sólo un susurro, como ella en un momento lo califica, le molesta y llama a la recepción para quejarse:

- Un saxofón. Un piano. Algo entre los dos. [...] / ¿ ¿La música de la mañana? - repitió ella sin comprender?

- Así es - dijo él, sin inmutarse.

- Pero yo no quiero oír su música de la mañana - dijo, enunciando con todo cuidado cada palabra.

- No hay nada que podamos hacer desde aquí -. Son los ejercicios matutinos. (68) 
Catedral Tomada: Revista de crítica literaria latinoamericana / Journal of Latin American Literary Criticism Espacios de salvación y prisión: Memoria narrativa y "colindancia” en La ciudad de los hombres de Cristina Rivera Garza

Al colgar el teléfono la protagonista queda agobiada. En este punto de la narración, ya está al tanto de que las mujeres son consideradas una amenaza para la ciudad, pero también, se da cuenta que los hombres igualmente están sujetos a cierto tipo de control y vigilancia, lo cual aumenta su temor:

Cuando se dirigió a la ventana que daba a un gran patio interior se sorprendió al ver a un grupo de hombres jóvenes sosteniendo libros entre las manos. Caminaban y leían al mismo tiempo. Daban la impresión de ser monjes o eunucos o seres que pertenecían a otro mundo. Quiso tomar fotos pero recapacitó: imposible saber si eso estaba permitido o no. [...] No era para tanto, se lo repetía a sí misma, pero no pudo detener el llanto. (69)

El control absoluto de una sociedad y la exclusión de un grupo de personas, evidencia una posición crítica que puede ser analizada desde el concepto de "biopoder" planteado por Michel Foucault. Este poder, que según Foucault se origina en un período posterior al siglo XVIII, se define como aquel que busca el control total de poblaciones y que se puede ejercer a través sistemas de poder como el racismo. En el caso del relato de Rivera Garza, aunque las mujeres no son excluidas por su "raza", sí lo son por su género. Esta exclusión que las lleva a confinarse en la selva, evidencia varias de las prácticas de control planteadas por Foucault. De acuerdo al filósofo, en el caso de sociedades racistas dar "muerte" a los otros es indispensable para establecer y mantener el poder, aunque no siempre esta muerte sea un acto literal:

Desde luego, cuando hablo de dar muerte no me refiero simplemente al asesinato directo, sino también a todo lo que puede ser asesinato indirecto: el hecho de exponer a la muerte, multiplicar el riesgo de muerte de 
algunos o, sencillamente, la muerte política, la expulsión, el rechazo, etcétera [...]. (Defender 9)

Las periodistas en la sociedad expuesta por el relato son rechazadas y aisladas. Su "muerte" se da a través de su aislamiento en la selva, la incomunicación y la consecuente pérdida del entendimiento como es discutido a continuación.

Si bien la protagonista logra reunirse con sus colegas periodistas, como tanto lo deseaba, este encuentro no le provee ningún tipo de información sobre sus vidas previas. Lo que sí logra es corroborar sus premisas acerca del poder que ejerce la "ciudad" sobre sus habitantes y sobre aquellas que habitan la selva que la rodea. Al narrar esta reunión en su reportaje al editor, la periodista es más explícita sobre el destino final de las periodistas: "Ahí, en uno de esos efímeros poblados, sobreviven hasta la fecha dos de las tres periodistas que no lograron salir de la Ciudad de los Hombres" (La frontera 75). Las mujeres viven alejadas en "la colindancia" y del control inmediato de la ciudad, sin embargo, esto no quiere decir que están en completa libertad, ya que en ella han perdido la capacidad para comunicarse y tomar decisiones propias:

- ¿Huyen? - les pregunté.

- ¿De qué? - me preguntaron a su vez, intrigadas.

- ¿Cómo es que decidieron quedarse aquí? - continué.

- Uno no decide nunca este tipo de cosas, balbuceó una de ellas [...] Este tipo de cosas pasan. Eso. Pasan. Y, luego, dejan de pasar.

- Pero algo ha de haber sucedido- insistí-. Algo ha de haber precipitado esto que pasa y que, luego, eventualmente, dejará de pasar.

- Con toda seguridad - murmuró una de ellas -. Algo ha de haber pasado.

Sí. (76) 
Catedral Tomada: Revista de crítica literaria latinoamericana / Journal of Latin American Literary Criticism Espacios de salvación y prisión: Memoria narrativa y "colindancia” en La ciudad de los hombres de Cristina Rivera Garza

En la "colindancia" las mujeres no tienen control, ya que a pesar de que han cruzado hacia otro espacio, siguen estando bajo el control de la ciudad. Como se ha planteado hasta ahora en este trabajo, las heterotopías funcionan como un contraste a las utopías. Además, de acuerdo con lo que argumenta Foucault sobre estos espacios, le interesan en la manera neutralizan, sospechan y contradicen a otros espacios. En su delineamiento de los seis principios heterotópicos, sin embargo, sólo en algunas ocasiones las plantea como lugares que están marcados por el género ${ }^{12}$. Es de esta forma que el relato de Rivera Garza presenta las heterotopías como un reflejo distinto de esas ubicaciones utópicas ${ }^{13}$ formuladas por Foucault. En "La ciudad de los hombres" las "anti-ciudades" son lugares dispersos e inconstantes; esta "colindancia" no obstante, no deja escapar a las mujeres ni les da salvación; las mantiene atrapadas en las esquirlas de la ciudad.

En la "colindancia" además se convierten en "inhumanas" pierden sus habilidades comunicativas, las cuales son intrínsecas de su profesión: "Me tomó tiempo darme cuenta de lo obvio: las ex periodistas no entendían ya mis preguntas y yo estaba incapacitada todavía para entender sus respuestas" (76). La incomprensión entre ellas por su estadía en la selva, queda evidente en una de las pesquisas que lleva a cabo la protagonista sobre "la Inhumana", ser que descubre a partir de las indagaciones que hace sobre las reporteras. La información que encuentra de "la inhumana", un ser aparentemente "nada familiar", forma parte de los reportajes que recibe el editor posteriormente:

Engrapadas a las páginas en blanco o pegadas con resistol, eran notas amarillentas en las que, años atrás, se había documentado la aparición

\footnotetext{
${ }^{12}$ El primer apartado es claramente una excepción: "In the so-called primitive societies, there is a certain form of heterotopia that I would call crisis heterotopias, i.e., there are privileged or sacred or forbidden places, reserved for individuals who are, in relation to society and to the human environment in which they live, in a state of crisis: adolescents, menstruating women, pregnant women. the elderly, etc." (Foucault, "The Order").

13 "But among all these sites, I am interested in certain ones that have the curious property of being in relation with all the other sites, but in such a way as to suspect, neutralize, or invert the set of relations that they happen to designate, mirror, or reflect" (Foucault. "The Order").
} 
súbita de un ser salvaje en la ciudad. Sin hablar su lengua y encorvada, la figura parecía provenir de muy lejos. Un lugar fuera del tiempo. Un lugar sin contextos humanos [...]. En las fotografías a veces daba la impresión de ser mujer [...] en otras más no se parecía a nada familiar. La Inhumana, le había puesto desde el inicio, conservando el artículo en femenino. (73)

Las descripciones se asemejan a las reporteras que residen en las "anticiudades". A partir de este hallazgo, la periodista teme convertirse en este ser en las últimas líneas del relato cuando está a punto de ser abandonada en la selva por el chofer: "Asumí que me abandonaría a la orilla del camino de un momento a otro. Ésa era su estrategia: abrir la puerta y depositar al inicio de la nada, que era en realidad el inicio del todo, un todo inconmensurable y verde, a la todavía humana $^{14 "}$ (83). Las mujeres en el relato no son solamente expulsadas de la ciudad, sino que también son representadas como seres salvajes, monstruosos como "La Inhumana", como lo detallan los reportajes posteriores al editor de la reportera.

Estas representaciones dan cuenta de cómo han sido vistas las selvas, como territorios incivilizados en la historia y literatura latinoamericana del siglo XIX. Al respecto, Domingo Faustino Sarmiento, en repetidas ocasiones, clasifica a la "barbarie" como un lugar aislado que no permite la "civilización": “¿Dónde colocar la escuela para que asistan a recibir lecciones los niños diseminados a diez leguas de distancia en todas direcciones? Así, pues, la civilización es del todo irrealizable, la barbarie es normal [...]" (Sarmiento 20). Cabe destacar que, si bien este tipo de pensamiento es fundador de toda una tradición literaria, política, social en Latinoamérica también lo es la representación de las mujeres como salvajes y/o monstruosas en la literatura. De acuerdo a la filósofa Rosi Braidotti en Nomadic Subjects la caracterización de las mujeres en el pensamiento

\footnotetext{
${ }^{14}$ El énfasis es mío.
} 
Catedral Tomada: Revista de crítica literaria latinoamericana / Journal of Latin American Literary Criticism Espacios de salvación y prisión: Memoria narrativa y "colindancia” en La ciudad de los hombres de Cristina Rivera Garza

Occidental — desde la época de Aristóteles — ha mantenido lo femenino fuera y dentro del espacio literario con características diferenciales devaluadas:

The association of women with monsters goes back as Aristotle who, in The Generation of Animals, posits the human norm in terms of bodily organization based on the male model. Thus, in reproduction, when everything goes according to the norm a boy is produced; the female happens when something goes wrong or fails to occur in the reproductive process. The female is therefore an anomaly [...]. (79)

El estudio crítico de Braidotti ayuda a entender la concepción de la mujer como un "otro", un ser monstruoso, desde el pensamiento científico que rápidamente fue adoptado en distintos ámbitos y épocas de la historia universal ${ }^{15}$. Es importante tener en cuenta que existen múltiples perspectivas sobre las mujeres en el contexto latinoamericano ${ }^{16}$. La postura que se plantea en "La ciudad de los hombres" - a través del lente de la memoria narrativa que se propone en este estudio - apunta a hacer una crítica a la influencia europea que favorece Sarmiento y que se ha posicionado históricamente en Latinoamérica. En el relato, la selva sirve como depositario, lugar en el que son confinadas las mujeres, no sólo en razón de su género, sino por ser, por tener la habilidad, la asignación de comentar, reportar, criticar el "proyecto".

La ciudad se establece como un espacio "civilizado" y desde el género masculino, bajo un propósito en común: excluir a las mujeres. Quienes cuestionan de alguna manera este espacio y no comparten sus valores y objetivos, son excluidas, en femenino, porque lo que es claro es que en este proyecto de ciudad no caben las mujeres. Este acto de marginación a la selva resulta fatal no sólo porque pierden sus habilidades comunicativas, sino también porque allí peligra

\footnotetext{
${ }^{15}$ La concepción de la mujer como un ser nómada es también productivo para esta discusión. Sin embargo, me limito en este momento a su estudio de la mujer como un ser "monstruoso".

${ }^{16}$ Concepciones de los pueblos originarios, por ejemplo.
} 
sus vidas. Al respecto insinúa el "Director" del "Hospital para Enfermos Crónicos" cuando la periodista lo entrevista:

- Ahí está el cementerio, ¿alcanza a distinguirlo?

- preguntó el Director mientras se aproximaba a ella por la espalda. El dedo índice, enhiesto. Algo inidentificable del otro lado de la ventana-. Las criptas siempre desaparecen bajo el embate de las plantas. Supongo que eso es lo bueno de tener un cementerio en la selva - concluyó. ( $\mathrm{La}$ frontera 79)

La afirmación del director del hospital acerca del ocultamiento en la selva del cementerio es otra de las maneras que la narración presagia el destino final de la reportera, protagonista del relato. De acuerdo con Foucault, los cementerios son también un tipo de heterotopía; es relevante en este momento destacar que las heterotopías han sido analizadas por críticos y filósofos como espacios de resistencia a sistemas hegemónicos ${ }^{17}$. Las “anti-ciudades" en el cuento de Rivera Garza permiten explorar las complejidades de estos lugares, que caben dentro del marco teórico de Foucault, pero que evidencian sus inconsistencias, las cuales también son destacadas por Robert J. Topinka desde otras coordenadas en su trabajo crítico sobre estos espacios: "Indeed, the paradox of heterotopias is that they are both separate from and yet connected to all other spaces. This connectedness is precisely what builds contestation into heterotopias" (60).

Esta premisa matizada por Topinka resalta lo difícil que es definir los espacios heterotópicos, pero también desde este lente teórico podemos explorar cómo la obra de Rivera Garza se posiciona a partir de una representación de

${ }^{17}$ Veáse: Benjamin Genocchio, "Discourse, Discontinuity, Difference: The Question of 'Other' Spaces," en Postmodern Cities and Spaces, Katherine Gibson \& Sophie Watson (eds.), 35-47 (Cambridge, MA: Blackwell Publishers, 1995), Kevin Hetherington, The Badlands of Modernity (London: Routledge, 1997); Bruno Bosteels, "Nonplaces: An Anecdoted Topography of Contemporary French Theory," Diacritics, vol. 33, nos. 3-4, 117-39 (Fall-Winter 2003); Peter Johnson, "Unravelling Foucault's 'different spaces," History of the Human Sciences, vol. 19, no.4 (November 2006), 75-90. 
Catedral Tomada: Revista de crítica literaria latinoamericana / Journal of Latin American Literary Criticism Espacios de salvación y prisión: Memoria narrativa y "colindancia” en La ciudad de los hombres de Cristina Rivera Garza

género en contra de divisiones y oposiciones extremas. Esta propuesta es evidente en el caso del cementerio que está dentro de la selva y las "anti-ciudades". Foucault señala en "Of Other Spaces" que el cambio de localización del cementerio del centro de la ciudad, hacia las afueras en culturas occidentales, es un ejemplo que refleja las concepciones culturales y políticas de la muerte en distintos contextos históricos:

The cemetery is certainly a place unlike ordinary cultural spaces. It is a space that is however connected with all the sites of the city, state or society or village, etc., [...] Until the end of the eighteenth century, the cemetery was placed at the heart of the city, next to the church. [...] it is from the beginning of the nineteenth century that everyone has a right to her or his own little box for her or his own little personal decay, but on the other hand, it is only from that start of the nineteenth century that cemeteries began to be located at the outside border of cities. In correlation with the individualization of death and the bourgeois appropriation of the cemetery, there arises an obsession with death as an illness. (Foucault, “The Other”)

En el cuento de Rivera Garza, este sitio -el cementerio- responde a un contexto en donde la muerte ya no es concebida como parte de la ciudad y es marginada. Sin embargo, también expone otro nivel de comprensión de los espacios heterotópicos dentro de la selva y su cementerio: la imposibilidad de escapar de ellos.

La "colindancia" de Cristina Rivera Garza en "La ciudad de los hombres" busca cuestionar, desfigurar y/o desubicar un centro. La crítica Marie José Hanaï en su exhaustivo análisis de La frontera más distante, propone que la autora forma parte de una generación de ruptura: “[...] que se puede asimilar con los 
'escritores fronterizos' ${ }^{18}$, radicados geográficamente en los estados fronterizos mexicanos; pero también en un movimiento de ruptura frente a los cánones, ruptura que implica una relación lúdica con las convenciones literarias, a las cuales no obedecen, revisan y reescriben" ("Imaginar y franquear").

La revisión de los cánones que señala Hanaï se presenta en "La ciudad de los hombres" al reescribir "civilización vs. barbarie" desarrollando la historia en dos espacios: "ciudad vs. selva". Al revisar esa memoria narrativa también plantea que lo que se toma por oposición absoluta no lo es por completo, debido a que existen espacios que alteran la lógica binaria como la "colindancia". Esta propuesta ${ }^{19}$ ejemplifica el rechazo de los límites, de la represión institucional y de los territorios restrictivos. La subversión del canon presente en este cuento, propone liberarse de una tradición que difundió la división en naciones latinoamericanas, a través de prácticas ideológicas violentas y/o la opresión política. Rivera Garza da cuenta de esto, de su huella, al igual que de su propia postura que no es del todo esperanzadora como lo deja ver desde un inicio en "La ciudad de los hombres".

La visita de la reportera a la ciudad es oficial, pero no es tratada como tal. El recibimiento hostil no es sólo por parte de las autoridades, sino también por los mismos ciudadanos, como lo ejemplifica el trato que le dan varios hombres cuando llega por primera vez al aeropuerto de la ciudad:

Iba distraída y a disgusto, en efecto. Iba en contra de su voluntad. Eso lo debió haber notado el hombre que, veloz, pasó a su lado, tratando de arrebatarle la bolsa de su hombro. Esto también lo percibió con toda seguridad el otro hombre que corriendo en sentido contrario, intentó llevarse su maleta $[\ldots]$ cuando apareció el tercer hombre, quien repitió su

\footnotetext{
${ }^{18}$ De acuerdo a Marie José Hanaï, “Apelación utilizada por los críticos B. Rodríguez y R. L. Williams en La narrativa posmoderna en México, Xalapa, Universidad Veracruzana, 2002".

${ }^{19}$ La "colindancia" también se encuentra en otros trabajos de Cristina Rivera Garza, como en sus publicaciones periodísticas y en el libro Ningún reloj cuenta esto (2002).
} 
CATEDRAL Tomada: Revista de crítica literaria latinoamericana / Journal of Latin American Literary Criticism Espacios de salvación y prisión: Memoria narrativa y "colindancia” en La ciudad de los hombres de Cristina Rivera Garza

nombre varias veces y la tomó por los hombros al notar su falta de reacción, ella no pudo hacer otra cosa más que echarse a llorar. ( $L a$ frontera 59)

El episodio citado da cuenta del rechazo, del acecho de la mujer y el disgusto de la periodista al ser asignada por el periódico para hacer el reportaje, como bien lo describe la protagonista en los fragmentos iniciales del relato. Ella llega a la ciudad de los hombres en contra de su voluntad y sólo acepta el reportaje debido a que le es conveniente: "Tenía deudas y también aspiraciones, y ambas cosas la habían obligado a sonreír sin demasiada ironía cuando le entregaron los boletos en la mano" (57). La ciudad no le interesa. Desde su llegada la protagonista sufre una serie de incidentes amenazantes que presagian su eventual marginación a la "colindancia".

Su llegada a la ciudad es fatal. Si bien la reportera toma de una manera práctica la tarea asignada de hacer el reportaje sobre la ciudad de los hombres, desde su llegada a la ciudad, el temor y las pesadillas no la abandonan. Sus sueños, por ejemplo, relatan situaciones donde pierde el control, fuerzas inexplicables la dominan y desaparecen. La narración de las dos pesadillas es enunciada de la siguiente manera: "Esa noche la periodista soñó [...]" (60 y 68). En la primera pesadilla la reportera sueña que levita y no tiene dominio: “[...] No tenía deseos de volar [...] La sensación de ligereza que, al inicio sólo era motivo de exaltación, pronto se convirtió en suspicacia y, luego, casi de inmediato, en terror" (60). En el segundo sueño - y último - el pánico se manifiesta a través de una versión miniatura de ella misma dentro de una casa gigante:

Calculó que le faltaban unos tres metros cuando se topó con un espejo: había una mujer pequeñísima en él. Una muñeca o un títere. Una especie de gnomo vestido de mujer. Le tomó tiempo entender que eso era ella misma. Y cuando por fin lo entendió, el terror fue tanto que se echó a 
correr. El efecto de la ampliación de la casa se multiplicó entonces y pronto, la mujer se vio a sí misma desaparecer. (68)

En las dos pesadillas el terror es un elemento recurrente y enfatiza la pérdida de control que tienen las mujeres en la ciudad. Estas emociones evocan las historias de las periodistas. Por otro lado, las afirmaciones de la protagonista sobre sus colegas aisladas en la selva señalan que éstas han perdido el entendimiento y la memoria. Como se ha mencionado previamente, las periodistas no recuerdan cómo ni por qué llegaron a la selva, por lo que a la pregunta de la protagonista sobre por qué decidieron quedarse en la selva, ellas responden como ya se citó "Uno no decide este tipo de cosas" (76). La "colindancia" ha transformado a estas mujeres en seres incapaces de comunicarse. La protagonista es la única que deja constancia de su desaparición en los reportajes que le envía al editor, los cuales le llegan sin explicación; el relato no da pistas de cómo éstos son enviados. Esta ambigüedad enfatiza el terror y misterio de la expulsión de la reportera a la selva hacia el final del relato. Durante la noche del séptimo día, el cual debía ser el último de la protagonista en la ciudad, el taxi programado para llevarla al aeropuerto llega puntual a su hotel. En camino a su destino el taxi se desvía, se interna en la selva, para confinarla ahí. Al entrar a la selva la reportera sabe que ya no podrá salir de ahí: "Sabía lo que tenían planeado para mí porque no era algo distinto a lo que les sucedió a las dos o tres periodistas anteriores [...] Asumí que me abandonaría a la orilla del camino de un momento a otro" (83). La escasez de detalles sobre la expulsión de la protagonista - como lo ejemplifica la cita previa - no elimina el final fatal de la protagonista. Es recluida en la selva.

La protagonista deja de comunicarse con el mundo exterior: "Dejaron de tener contacto con ellas casi desde el momento en que partió. Al jefe de Redacción [editor del periódico donde trabaja la protagonista] le extrañó no recibir información alguna respecto de su llegada y no dejó de sentir un resquemor creciente [...] Imaginó lo peor, por supuesto" (76). A pesar de esto el "Jefe" no procede a investigar sobre el paradero de la periodista: "Después de 
Catedral Tomada: Revista de crítica literaria latinoamericana / Journal of Latin American Literary Criticism Espacios de salvación y prisión: Memoria narrativa y "colindancia” en La ciudad de los hombres de Cristina Rivera Garza

dudarlo mucho, decidió esperar un par de días más. No quería provocar pánico entre los empleados ni tropiezos de corte diplomático entre las dos ciudades" (77). Evidentemente el "Jefe" tiene claridad sobre las complicaciones que puede causar si busca a la reportera. Esta decisión de esperar recibir noticias demuestra el miedo a posibles conflictos que existen entre el extranjero y la ciudad de los hombres. De igual modo, la actitud del editor es tímida, dejando en segundo plano la seguridad de la reportera, lo que reproduce el comportamiento de los hombres en la ciudad.

Adicionalmente, la reportera fue enviada a la ciudad de los hombres con la pretensión de que por el hecho de "ser mujer", o teniendo en cuenta su "perspectiva femenina", los reportajes que llegara a hacer tendrían un "éxito asegurado", sin embargo, esta pretensión no llega a feliz término. Con base al relato, la desaparición de una tercera o cuarta periodista, evidencia los fracasos que han tenido los periódicos para investigar y reportar sobre la ciudad de los hombres. Así, por tanto, la ciudad se resiste a ser cuestionada y expuesta al escrutinio internacional, por lo que, a pesar de ser sólo un "proyecto" se muestra inquebrantable.

La "memoria narrativa" delineada en este artículo - "civilización y barbarie" - evoca también otras obras de la tradición literaria latinoamericana que exploraron las selvas como "barbarie", tales como La vorágine de José Eustasio Rivera y Los pasos perdidos de Alejo Carpentier. La memoria sobre estas obras la podemos identificar en el relato, aunque Rivera Garza no referencia una cita directa a ellas. La forma que la autora distingue a la selva es la que evidencia ese eco literario; este espacio es otra de las vertientes de la memoria narrativa, específicamente su incuestionable color: "Ésa era su estrategia: abrir la puerta y depositar al inicio de la nada, que era en realidad el inicio del todo, un todo inconmensurable y verde ${ }^{20}$, a la todavía humana" (La frontera 83). Es necesario resaltar la conexión con lo verde en el relato, con esa selva donde es abandonada

\footnotetext{
${ }^{20}$ El énfasis en itálicas es mío.
} 
la reportera y que se plantea como el "inicio de todo". Esta insinuación es similar a lo que Roberto González Echevarría propone sobre la obra de Domingo Faustino Sarmiento en "III. El mundo perdido redescubierto" en el libro Mito y Archivo. Una teoría de la narrativa Latinoamericana, el crítico argumenta que al ahondar en la memoria cultural argentina, convertirla en su objeto de estudio, Sarmiento en Facundo conceptualiza el origen argentino a través de la pampa verde: "Aunque Sarmiento alude con frecuencia a la historia española e incluso a la historia india de Argentina, el origen es la pampa que aparece como un inicio absoluto, anterior a la historia [...]” (González Echevarría 172). Echevarría explora la conexión de la pampa, la historia literaria latinoamericana, el interés de Sarmiento por Facundo Quiroga y la influencia de éste en su obra (González Echevarría 181).

Aunque este regreso al "origen" para ella es también el origen de su prisión, es un reencuentro con un inicio histórico anterior como lo propone Echeverría; la pampa y la selva son la memoria narrativa evocada en el relato de Rivera Garza quien alude a esa tradición, a esos lugares marginalizados, calificados como salvajes y que aprisionan. Esta memoria narrativa resalta que la rememoración no se da en el texto a través de un diálogo sin conflictos. La conceptualización de las “anti-ciudades" como prisiones o lugares fatídicos, trae a la memoria en particular las afirmaciones del poeta Arturo Cova ${ }^{21}$ en La vorágine sobre la selva quien también la concibe como fatídica: "Déjame huir, oh selva, de tus enfermizas penumbras, formadas con el hálito de los seres que agonizaron en el abandono de tu majestad. ¡Tú misma pareces un cementerio enorme donde te pudres y resucitas!" (118). Cristina Rivera Garza vuelve a esa tradición "verde" que data desde el siglo XIX en Latinoamérica, retoma la imagen de la selva como cementerio, pero también como caserío y el como el "inicio de todo". La reportera desea huir, pero no lo logra. Este fracaso plantea otro, el de la perduración de esa tradición divisora en el imaginario latinoamericano entre civilización y naturaleza, que ha traído desde la colonización hasta la actualidad consecuencias irreversibles

${ }^{21}$ Protagonista de La vorágine. 
Catedral Tomada: Revista de crítica literaria latinoamericana / Journal of Latin American Literary Criticism Espacios de salvación y prisión: Memoria narrativa y "colindancia” en La ciudad de los hombres de Cristina Rivera Garza

en las naciones latinoamericanas, tales como la discriminación y el rechazo a las raíces originarias.

La escritura, la asignación periodística, los ecos literarios, como se ha destacado a través del marco de la memoria narrativa, son los puntos cardinales desde donde Rivera Garza prefiere plantear sus reflexiones acerca de la tradición literaria latinoamericana. El final sin resolución de "La ciudad de los hombres" se vincula con esta premisa: "Estoy segura de que el tiempo se hará cargo de todo lo demás. Mientras tanto escribo. Mientras tanto me guarezco en esta choza y escribo. [...] Pronto, también, dejaré de entender. Cuando alguien me arrebate este pedazo de papel de entre las manos no entenderé ya más" (La frontera 83). La protagonista no logra salir de la selva. A pesar de estar fuera del "proyecto" está aprisionada en su "colindancia", aunque este espacio represente una contienda con la ciudad utópica de los hombres.

Rivera Garza enfatiza la relevancia de la memoria a través de la escritura que lleva a cabo la protagonista en la "colindancia". Esta evocación va en contra de discursos canónicos, como se ha argumentado a lo largo de este estudio, que también están relacionados con el poder y la ciudad. Esta estrategia nos dirige a enfrentar la manera que se desarrolla la relación de la mujer con lo que Ángel Rama denominó, la ciudad letrada ${ }^{22}$. La ciudad, ese espacio de los proyectos nacionales del siglo XIX - como el de Sarmiento - el de la modernización y de los proyectos revolucionarios latinoamericanos, está marcada por el género masculino; la mujer no tenía lugar en este espacio que había estado vinculado al poder de los intelectuales, los hombres, como argumenta Soledad Falabella Luco: "[...] este espacio ha estado tradicionalmente vinculado a una elite metropolitana marcada por género, clase, raza, y un 'aura sacerdotal', como argumenta Ángel Rama en La ciudad letrada - pensemos el funcionamiento de los "Padres de la

22 “[...] una ciudad letrada que componía el anillo protector del poder y el ejecutor de sus órdenes: una pléyade de religiosos, administradores, educadores, profesionales, escritores y múltiples servidores intelectuales, todos esos que manejaban la pluma, estaban estrechamente asociados a las funciones del poder [...]" (Rama 32) 
Patria"- (176). Las mujeres han sido excluidas de la ciudad- el centro de la civilización como se ha argumentado -a través de distintos discursos fundacionales de América Latina. Tomando en cuenta los argumentos de Falabella Luco y Rama, la ciudad, la tradición, el canon, han estado marcados por un género y su poder discursivo. La exclusión de la mujer de la "letra", de la escritura es retomada en este relato de Rivera Garza. Los reportajes que recibe posteriormente el editor complican esta inescapable evocación. Estos artículos periodísticos son una fusión entre el diario personal, reportajes y cartas; incluyen detalles de la ciudad que ninguna reportera puso en papel, pero también sus reacciones personales sobre el miedo, la amenaza y algunos episodios de llanto como respuesta a éstos. La salida de las cartas/reportajes de las "anti-ciudades" son la resistencia al "proyecto", a la ciudad y a la "civilización" en masculino.

Si bien, la reportera no logra liberarse físicamente, sí lo hace a través de la escritura, ésta sí consigue la libertad. En el prefacio de The Order of Things Foucault hace referencia a la conexión entre la escritura, el lenguaje en particular y los espacios:

Heterotopias are disturbing, probably because they secretly undermine language, because they make it impossible to name this and that, because they shatter or tangle names, because they destroy 'syntax' in advance, and not only the syntax with which we construct sentences but also that less apparent syntax which causes words and things (next to and also opposite one another) to 'hold together'. (xviii)

Esta disfunción del lenguaje en las heterotopías evoca el comportamiento y el lenguaje limitado de las periodistas, ya que no logran transmitir sentido alguno: no saben reconstruir los sucesos ni recuerdan quien las llevó a la selva. A pesar de ello, los reportajes sí logran trascender, es la escritura de la periodista la que denuncia las amenazas, el control, la represión y el autoritarismo de la ciudad; 
Catedral Tomada: Revista de crítica literaria latinoamericana / Journal of Latin American Literary Criticism Espacios de salvación y prisión: Memoria narrativa y "colindancia” en La ciudad de los hombres de Cristina Rivera Garza

aunque su narración es algunas veces breve, no es sino hasta el desenlace del relato que la existencia de los reportajes afirma su relevancia política.

La protagonista de "La ciudad de los hombres" no resiste la selva, sino la “civilización”, al contrario de lo que se presenta en La vorágine. Esta propuesta acentúa cómo los replanteamientos de Rivera Garza van más allá de la cita textual. Las cartas/reportajes le permiten a la autora dialogar con múltiples contextos y textos. Es una reafirmación de su interés por hacer memoria, pero también para reevaluar el pasado. En el relato de Rivera Garza sólo la escritura puede escapar. Sin embargo, sigue siendo fatal para las mujeres y esta es la memoria que la autora resalta en su relato. La selva, "la colindancia", "las anticiudades", el cementerio, traen a discusión una memoria narrativa que reflexiona sobre los cruces a espacios que institucionalmente se proponen como excluyentes.

A través de la figura de la reportera en "La ciudad de los hombres" se evoca un encuentro de discursos literarios, desde un espacio que exhibe oposiciones y divisiones. Estas características no sólo están presentes en este cuento, en otros relatos de La frontera más distante imperan ecos de esta "selva" o "barbarie”, como por ejemplo en: "El rehén”, "La mujer de los Cárpatos", “Simple placer. Puro placer", "El perfil de él” y en forma antagónica en "Fuera de lugar".

\section{La salvación y prisión de las mujeres en "la colindancia": conclusiones.}

Aunque otros cuentos podrían haberse incluido en la investigación que se expone en este artículo, "La ciudad de los hombres" fue escogido porque dialoga con respecto a la denuncia del estado de marginalización de las mujeres en la ciudad, "la civilización", especialmente en no ser sujetas de conocimiento -se les excluye de la escritura y la comunicación. Las mujeres son presentadas como 
sujetos sin derecho a la denuncia, la escritura y reducidas a la invisibilidad. Oswaldo Estrada, en su extensa investigación sobre la obra de Rivera Garza argumenta que ésta se caracteriza por los desafíos que propone:

Distancing themselves from their predecessors, writers such as Cristina Rivera Garza (1964), [...] challenge our notions of women's literature with transgressions of all types, with controversial explorations of gender and sentimentalism in contemporary societies, and with the problematic construction of identities in globalized or deterritorialized environments. (Estrada 64)

Así, por tanto, otro punto de diálogo es que este plantea retos tales como el de encontrar la salvación en la denuncia, se preguntan por la memoria narrativa desde la "colindancia", afirmando en ese sentido, debates y oposiciones. Siguiendo lo anterior, el término memoria narrativa sitúa un corpus que ha dejado huella en el pensamiento crítico y literario latinoamericano.

El binomio "civilización y barbarie" en "La ciudad de los hombres" que plantea la autora, es re-evaluado a partir de contextos espaciales asépticos, de las esquirlas de las utopías y apoyándose en la "colindancia". Es así como se evidencian una posición discursiva de denuncia en la que se propone representaciones de las mujeres como sujetos marginalizados, deshumanizados y que no pueden pertenecer al orden establecido. Este lugar desde la "colindancia" en donde se encuentran las mujeres, apunta a de-construir los modelos binarios, lo cual permite replantear las ideologías dominantes propuestas en el siglo XIX por figuras de poder y que continuaron en el siglo XX como argumenta Echeverría y Rama.

La memoria narrativa en el análisis planteado se convierte en un eje de análisis, comprendiéndola desde los espacios colindantes, espacios que resultan ser tanto salvación como prisión para las mujeres. Si bien la "colindancia”, es una 
Catedral Tomada: Revista de crítica literaria latinoamericana / Journal of Latin American Literary Criticism Espacios de salvación y prisión: Memoria narrativa y "colindancia” en La ciudad de los hombres de Cristina Rivera Garza

forma de desafiar el control, las clasificaciones, las divisiones, las fronteras, aunque las mujeres llegan a estar fuera de espacios de control y fugarse, coincide el hecho que siguen siendo vigiladas y no tienen la posibilidad de escapar.

En "La ciudad de los hombres" el relato surge desde estos márgenes, de espacios aislados, sin una referencia geográfica, para denunciar proyectos excluyentes y divisorios canónicos, tales como aquellos planteados en Facundo y/o La Vorágine, pero que se pueden encontrar en otras obras del canon latinoamericano; la evocación de estas obras en particular permite destacar particularidades de las imposiciones ideológicas de estos discursos. La permanencia de los géneros literarios planteada por Bajtín se basa en el diálogo con una tradición, un dialogismo que no deja de ser político. Rivera Garza hace memoria, evoca esos discursos en su obra para desde esa historia proponer narrativa que recuerde que también las mujeres fueron excluidas por la tradición.

\section{Bibliografía}

Aguilar Sosa, Yanet. "La escritura, una aventura extrema.” Entrevista en: El Universal. Enero 2007. http://archivo.eluniversal.com.mx/cultura/51037.html\#1. Consultado en línea: 29 de junio 2016.

Bajtín, M.M. Problems of Dostoevky's Poetics. Translated by Caryl Emerson. Minneapolis: University of Minnesota Press, 1984.

Benlimoud, Karim y, Alba Lara-Alengrin. Tres escritoras mexicanas: Elena Poniatowska - Ana García Bergua - Cristina Rivera Garza. Rennes: Presses Universitaires de Rennes, 2014. 
CATEDRAL TOMADA: Revista literaria latinoamericana / Journal of Latin American Literary Criticism Thania Muñoz Davaslioglu

Braidotti, Rosi. Nomadic Subjects - Embodiment and Sexual Difference in Contemporary Feminist Theory. New York: Columbia University Press, 1994.

Cantú, Irma. "El margen como centro: Exploración del espacio en dos cuentos de La frontera más distante de Cristina Rivera Garza". Ningún crítico cuenta esto. Ed. Oswaldo Estrada. México D.F: Ediciones Eón; Chapel Hill, N.C.: University of North Carolina at Chapel Hill: UC-Mexicanistas, 2010. PP. 349- 367.

Estrada, Oswaldo. “Against Representation: Women's Writing in Contemporary Mexico.” Hispanófila. Vol. 157. Diciembre 2009. PP. 63-78.

Falabella Luco, Soledad. ¿Qué será de Chile en el cielo?: Poema de Chile de Gabriela Mistral. Santiago: LOM ediciones, 2003.

Franco, Jean. The Modern Culture of Latin America: Society and the Artist. New York: Frederick A. Praeger, 1967.

Foucault, Michel. Defender la sociedad. Curso en el Collage de France (19751976). Buenos Aires: Fondo de Cultura Económica, 2001. PP. 217-238. . "Of Other Spaces: Utopias and Heterotopias." Trans. Miskowiec. Architecture/ Mouvement/Continuité. No 5: 1984. PP. 46-49. http://foucault.info/doc/documents/heterotopia/foucault-heterotopia-en-html Consultado en línea: 29 de junio 2016. . The Order of Things. New York: Vintage Books, 1994. English translation, originally published in French, 1966.

Fuentes, Carlos. La nueva novela hispanoamericana. México, D.F: Editorial Joaquín Mortíz, 1969.

González, Echevarría, Roberto. Mito y Archivo. Una teoría de la narrativa Latinoamericana. México: Fondo de Cultura Económica, 2000.

Hanaï, Marié-José. "Imaginar y franquear las fronteras en La frontera más distante de Cristina Rivera Garza." Escritural - Écritures d'Amérique latine. $\mathrm{N}^{\circ}$ 5. Marzo 2012. www.mshs.univ- 
Catedral Tomada: Revista de crítica literaria latinoamericana / Journal of Latin American Literary Criticism Espacios de salvación y prisión: Memoria narrativa y "colindancia” en La ciudad de los hombres de Cristina Rivera Garza

poitiers.fr/crla/contenidos/ESCRITURAL/ESCRITURAL5/ESCRITURAL_ 5_SITIO/PAGES/Hanai.html. Consultado en línea: 29 de junio 2016.

Herrera, Jorge Luis. "El amor es una reflexión, un volver atrás.” Entrevista con Cristina Rivera Garza”. Revista Universo del Búho. № 60, 2005. PP. 48-50. Kristeva, Julia. "Bajtín, la palabra, el diálogo y la novela." Intertextualité.

Francia en el origen de un término y el desarrollo de un concepto, selec. y trans., Desiderio, Navarro. Habana: Casa de las Américas, 1996. PP. 1-24.

Rama, Ángel. La ciudad letrada. Montevideo: ARCA, 1998.

Ramos, Julio. Desencuentros de la modernidad en América Latina: literatura y política en el siglo

XIX. Santiago: Editorial Cuarto Propio; San Juan: Ediciones Callejón, 2003.

Rivera Garza, Cristina, "Diaspóricos, fronterizos y electrónicos: un doble click sobre escrituras limítrofes entre México y Estados Unidos”. Memoria y censura en España e Hispanoamérica. Escritural - Écritures d'Amérique latine, № 5, marzo 2012. Consultado en línea: 29 de junio 2016. . La frontera más distante, México D.F: Tusquets Editores, 2008. . Ningún reloj cuenta esto, México D.F: Tusquets Editores, 2002.

Sarmiento, Faustino Domingo, Facundo - civilización y barbarie, Buenos Aires: Colección Austral, 1967.

Solís, Ricardo, "La escritura siempre nace comprometida: Cristina Rivera Garza”, en: La Jornada, 7 de julio, 2013. Consultado en línea: 9 de junio 2016. Topinka, Robert J., "Foucault, Borges, Heterotopia: Producing Knowledge in Other Spaces”, en: Foucault Studies, N 9, septiembre 2010, págs. 54-70. 